\title{
BMJ Open A systematic review on the effect of the organisation of hospital discharge on patient health outcomes
}

\author{
Bérengère Couturier, ${ }^{1,2}$ Fabrice Carrat, ${ }^{1,2}$ Gilles Hejblum ${ }^{1}$
}

To cite: Couturier B, Carrat F, Hejblum G. A systematic review on the effect of the organisation of hospital discharge on patient health outcomes. BMJ Open 2016;6:e012287. doi:10.1136/bmjopen-2016012287

- Prepublication history and additional material is available. To view please visit the journal (http://dx.doi.org/ 10.1136/bmjopen-2016012287).

Received 14 April 2016 Revised 2 August 2016 Accepted 12 September 2016

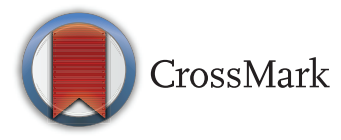

${ }^{1}$ Sorbonne Universités, UPMC Univ Paris 06, INSERM, Institut Pierre Louis d'Épidémiologie et de Santé Publique (IPLESP UMRS 1136), Paris, France ${ }^{2}$ AP-HP, Hôpital St-Antoine, Unité de Santé Publique, Paris, France

Correspondence to Bérengère Couturier; berengere.couturier@aphp.fr

\section{ABSTRACT}

Objective: The transition from hospital to home represents a key step in the management of patients and several problems related to this transition may arise, with potential adverse effects on patient health after discharge. The purpose of our study was to explore the association between components of the hospital discharge process including subsequent continuity of care and patient outcomes in the postdischarge period.

Design: Systematic review of observational and interventional studies.

Setting: We conducted a combined search in the Medline and Web of Science databases. Additional studies were identified by screening the bibliographies of the included studies. The data collection process was conducted using a standardised predefined grid that included quality criteria.

Participants: A standard patient population returning home after hospitalisation.

Primary and secondary outcomes: Adverse health outcomes occurring after hospital discharge.

Results: In the 20 studies fulfilling our eligibility criteria, the main discharge-process components explored were: discharge summary $(n=2)$, discharge instructions $(n=2)$, drug-related problems at discharge $(n=4)$, transition from hospital to home $(n=5)$ and continuity of care after hospital discharge $(n=7)$. The major subsequent patient health outcomes measured were: rehospitalisations $(n=18)$, emergency department visits $(n=8)$ and mortality $(n=5)$. Eight of the 18 studies exploring rehospitalisations and two of the eight studies examining emergency department visits reported at least one significant association between the discharge process and these outcomes. None of the studies investigating patient mortality reported any significant such associations between the discharge process and these outcomes.

Conclusions: Irrespective of the component of the discharge process explored, the outcome considered (composite or not), the sample size and the study design, no consistent statistical association between hospital discharge and patient health outcome was identified. This systematic review highlights a wide heterogeneity between studies, especially in terms of the component(s) of the hospital discharge process investigated, study designs, outcomes and follow-up durations.

\section{Strengths and limitations of this study}

This review is the first to date focusing on the relationship between components of hospital discharge organisation and subsequent patient health in a standard population returning home after hospitalisation.

- Quality assessment of the included studies was based on two combined tools to take account of the heterogeneity of the underlying study designs.

- The numerous discharge process elements investigated in the studies were categorised into several component types, and the impact of each component was assessed with regard to the corresponding health outcome(s) that was reported.

- A single author was involved in critical steps of the review (article selection, data abstraction, quality assessment of the included studies), and this constitutes a limitation of the study.

- The heterogeneity between studies on key issues such as hospital discharge components, study designs and outcomes (including follow-up durations), prevents quantitative synthesis and hampers consistent assessment of the impact of discharge organisation on patient health.

\section{INTRODUCTION}

\section{Rationale}

Since the pioneering studies of Forster et $a l^{12}$ in which around $20 \%$ of patients were reported to have experienced an adverse event within 2 weeks of hospital discharge, several studies have documented the rates of adverse health outcomes, such as emergency department visits and hospital readmissions, occurring during the post-discharge period. ${ }^{3-5}$ Therefore, return to home after a hospital stay should not viewed by hospital staff as the completion of patient management. Ideally, scheduling outpatient follow-up visits, promoting direct communication with primary care providers and ensuring transmission of the discharge summary, notifying pending test results at discharge, and, if necessary, arranging or suggesting outpatient post-discharge 
investigations, are various elements of the continuity of care after discharge that should be integrated within the hospital discharge process. Consequently, hospital discharge and subsequent continuity of care are complex interrelated processes involved in a patient's transition from hospital to home. One can hypothesise that some components of discharge organisation affect, at least partially, patients' subsequent healthcare, for example, the rate of rehospitalisation.

Several observational studies have highlighted deficiencies in the transition of care from the inpatient to the outpatient setting. Such studies focused on various aspects related to direct communication between inpatient and outpatient healthcare providers, ${ }^{6} 7$ discharge summaries (content, timeliness, transmission to an outpatient physician) ${ }^{8}{ }^{9}$ traceability and follow-up providers' information on pending test results at hospital discharge, ${ }^{10}{ }^{11}$ non-completion of recommended outpatient work-ups (diagnostic procedures, subspecialty referrals and laboratory tests) after hospital discharge, ${ }^{12}$ medication errors (omission or unjustified prescription) in discharge summaries, ${ }^{13}{ }^{14}$ drug-related problems after discharge ${ }^{15} 16$ and post-discharge follow-up outpatient visits. ${ }^{17}$ Only a few observational studies have investigated the potential association between elements of the hospital discharge process (and subsequent continuity of care) and patient health outcomes, ${ }^{19-21}$ and their reports are conflicting as regards the effect of such processes on patient health after discharge. Moreover, these studies considered patients with various admissions sources and/or discharge locations, not only their home, before and after hospital discharge. Other studies aimed at exploring the perspectives of hospital staff and/or primary care providers, ${ }^{22-24}$ or patient opinions, ${ }^{25-27}$ or both, ${ }^{28}{ }^{29}$ on hospital discharge and subsequent continuity of care. In particular, few studies have explored the association of such opinions on patient health outcomes such as rehospitalisations ${ }^{30} 31$ or rehospitalisations and emergency department visits. ${ }^{32}$

Finally, several reviews ${ }^{33-45}$ examined the effect of various interventions related to hospital discharge. One review was not a systematic review but highlighted several challenges, not necessarily directly focused on patient health outcomes. ${ }^{33}$ Three reviews concerned interventions on medication reconciliation at discharge,${ }^{34-36}$ and in two of them, ${ }^{34}{ }^{35}$ studies involving medication reconciliation at admission or during hospitalisation were also included. One review only concerned older patients with congestive heart failure and considered only interventions combining comprehensive discharge planning with post-discharge support. ${ }^{37}$ Two reviews focused on a single outcome, the rehospitalisation rate at 30 days after discharge. ${ }^{38} 39$ Conversely, one review focused on a single discharge component, telephone follow-up. ${ }^{40}$ There were four reviews in which some $^{41-43}$ or all $^{44}$ outcomes considered were not patient health measures, for example, discharge destination, ${ }^{41} 42$ length of stay, ${ }^{41-43}$ patient or health provider satisfaction ${ }^{41-43}$ and organisational outcomes (timeliness, accuracy, completeness and overall quality of the information transfer). ${ }^{44}$ One review categorised interventions according to the timing of these pre-discharge, postdischarge and bridging interventions, and included studies in which the destination of patients after discharge could be a nursing home or skilled nursing facility. ${ }^{45}$

As regards results obtained, the review on telephone follow-up interventions ${ }^{40}$ as well as the three reviews examining interventions related to medication reconciliation ${ }^{34-36}$ indicated that it was not possible to link these interventions to clinically significant improvements. Similarly, the review focusing on the 30-day readmission outcome was negative. ${ }^{38}$ Three reviews ${ }^{41}{ }^{42}{ }^{45}$ paint a rather mixed picture: the effectiveness of interventions on patients' health was not clearly demonstrated, and was at best modest. Three reviews ${ }^{37} 3943$ were more positive. First, based on the selection of randomised trials in which the intervention under study explicitly described one or more components that aimed to improve the handover of care between hospital and primary care providers during hospital discharge, the review of Hesselink et $a l^{43}$ indicates that a significant effect was found in favour of the intervention for one or several outcome measures in 25 of the 36 studies. Second, the systematic review of Phillips $e t a l^{37}$ reports that comprehensive discharge planning plus post-discharge support for older patients with congestive heart failure resulted in a $25 \%$ reduction in the relative risk of readmission, considering studies with a follow-up ranging from 3 to 12 months. Third, based on the inclusion of 42 randomised trials, with most studies relating to populations of patients at high risk, the meta-analysis of Leppin $e t a l^{39}$ indicates that peri-discharge interventions are associated with a reduction in the rehospitalisation rate at 30 days after discharge.

The perspectives varied widely from one review to another as regards the elements of the discharge process explored, the targeted population, the outcome (s) considered (including follow-up duration) and patient location after discharge. Considering the common case of a standard hospitalised patient from the general population returning home after discharge, the simple question 'Are there some discharge components specifically associated with health outcomes?', is not answered in the available reviews. De facto, we failed to identify a work providing a synthesis of the available knowledge on this question.

\section{Objective}

We conducted a systematic review to explore the potential association between elements of the hospital discharge process (including post-discharge continuity of care) and adverse outcomes (including healthcare resource consumption) in the post-discharge period, in a standard population of patients returning home. 


\section{METHODS}

The reporting of the systematic review is based on Preferred Reporting Items for Systematic Reviews and Meta-Analyses (PRISMA) guidelines ${ }^{46}$ (see online supplementary file 1).

\section{Eligibility criteria}

The predefined study inclusion and exclusion criteria are detailed in online supplementary file 2 .

\section{Information sources}

Initial searches in the databases were conducted between 1 March 2013 and 30 June 2013, with no limit considered for the start date, and all searches were updated on 13 July 2016. A combined search in the Medline database via PubMed and in the Web of Science was performed, using different search terms to cover exploration of the organisational process for hospital discharge and subsequent continuity of care. Four independent searches were conducted, which focused on discharge summary, medication reconciliation procedures (preferably at hospital discharge), global organisation of the discharge process and subsequent continuity of care, and care transition. We screened the bibliographies of review articles detected during the database searches (which were not eligible for inclusion) to identify any additional studies that had been missed during the database searches.

\section{Search strategies}

The queries made in the Medline and Web of Science databases are detailed in online supplementary file 3 .

\section{Study selection}

The eligibility of each retrieved article was assessed by one author (BC) in terms of its title, abstract and, if necessary, the full text. We decided a priori that in the case of doubt, a second reviewer (GH) would decide whether to include the study. The bibliography of each included study was screened to potentially identify any studies missed in the database searches. Whenever this resulted in the identification of an additional study, this screening process was repeated until no additional study was found.

\section{Data collection process}

The data collection process was conducted (by BC) using a standardised predefined data collection sheet and extracted data were checked.

\section{Data items}

The following information was extracted from each of the studies included: name of first author, journal, year of publication, component(s) of the discharge process investigated, study design, objective(s), setting, participants, sample size, method(s), description of the intervention and comparator (if applicable), main outcome measures, results, synthesis of the major results (ie, significant association or not between the component(s) of the discharge process investigated and patient health outcomes) and study limitations.

\section{Risk of bias in individual studies/quality assessment}

The methodological quality of the selected studies was evaluated (by BC) using two tools that have been proposed for assessing studies when the considered study set includes major differences in terms of experimental design (nb, we formalised a priori that in the case of doubt when rating the methodological quality of a study, a second author (GH) would be solicited for this rating). First, the Quality Assessment Tool for Quantitative Studies ${ }^{47}{ }^{48}$ rates study global quality as strong, moderate or weak. Second, the Mixed Methods Appraisal Tool-V.2011 ${ }^{49}$ grades the studies according to five categories, ranging from $0 \%$ (research questions not clearly stated), low $($ score $=25 \%)$, moderate $($ score $=50 \%)$ and high $($ score $=75 \%)$ to very high $($ score $=100 \%)$ methodological quality. Both tools have strengths and weaknesses. For example, the Quality Assessment Tool for Quantitative Studies automatically assigns a strong score to randomised controlled trials, irrespective of the quality of randomisation method and allocation concealment, while the Mixed Methods Appraisal Tool is limited to the evaluation of four items. Studies were finally ranked into three categories (weak, moderate or strong) according to a combination of the ranks determined by each of the two tools: in a first step, low and very low, moderate, and high and very high rankings with the Mixed Methods Appraisal Tool were recategorised as weak, moderate and strong, respectively, and then, the final ranking of a given study was chosen as the lowest rank of the two tools.

\section{Summary measures and synthesis of results}

A standard quantitative synthesis, that is, a meta-analysis, was deemed not to be appropriate because of wide variability in study designs, types of intervention (if applicable) and outcomes. Nevertheless, a synthesis of the results from the observational and interventional studies has been conducted and presented in the form of a summary table and figures with the aim of identifying emerging patterns relating components of the discharge process to patient health outcomes.

\section{Risk of bias across studies}

The possibility of publication bias resulting in more positive than negative studies being published may have affected the results of our review but could not be assessed.

\section{Additional analyses}

No prespecified additional analysis was performed. 


\section{RESULTS}

\section{Study selection}

The results of the eight initial independent searches (four major queries in each of the databases) identified 1144 publications, 890 after excluding 254 duplicates, of which eight studies were initially included (see online supplementary file 4 that indicates the references of fulltext articles excluded and details the corresponding reason) (figure 1). Screening the bibliographies of the initial included studies resulted in the inclusion of 10 additional studies. No additional studies were identified from the bibliographies of reviews identified during the database searches. Thus, the initial set consisted of 18 studies. ${ }^{31}{ }^{50-66}$ Update of the searches made on 13 July 2016 resulted in the inclusion of two additional studies. ${ }^{67} 68$

\section{Study characteristics}

The study characteristics are summarised in online supplementary file 5 . The 20 selected studies were published between 2001 and 2015 and were performed in the USA $(n=14)$, Canada $(n=4)$, Australia $(n=1)$ and the
UK $(n=1)$. Eleven studies were observational ${ }^{31}$ 50-58 67 and nine were interventional ${ }^{59-66} 68$ (including five randomised controlled studies). ${ }^{59-62} 68$ The interventions were mostly multifaceted interventions: four were pharmacist interventions ${ }^{59606364}$ and four focused on the transition from hospital to home, ${ }^{61} 626566$ while only one was an intervention with a single component (a post-discharge phone call) ${ }^{68}$

In 15 studies, patients were discharged from general medical and/or surgical units. Five studies targeted patients with heart failure, ${ }^{3150516567}$ with one study targeting a somewhat larger population. ${ }^{31}$

Sample sizes ranged from $83^{63}$ to $738^{62}$ patients for interventional studies and from $86^{52}$ to $938933^{53}$ patients for observational studies.

\section{Risk of bias within studies/quality assessment}

According to the Quality Assessment Tool for Quantitative Studies, 12 studies were rated as having a strong, ${ }^{31} 505153-5760-6267$ six a moderate ${ }^{52} 5859636668$ and two a weak ${ }^{6465}$ methodological quality (figure 2).
A
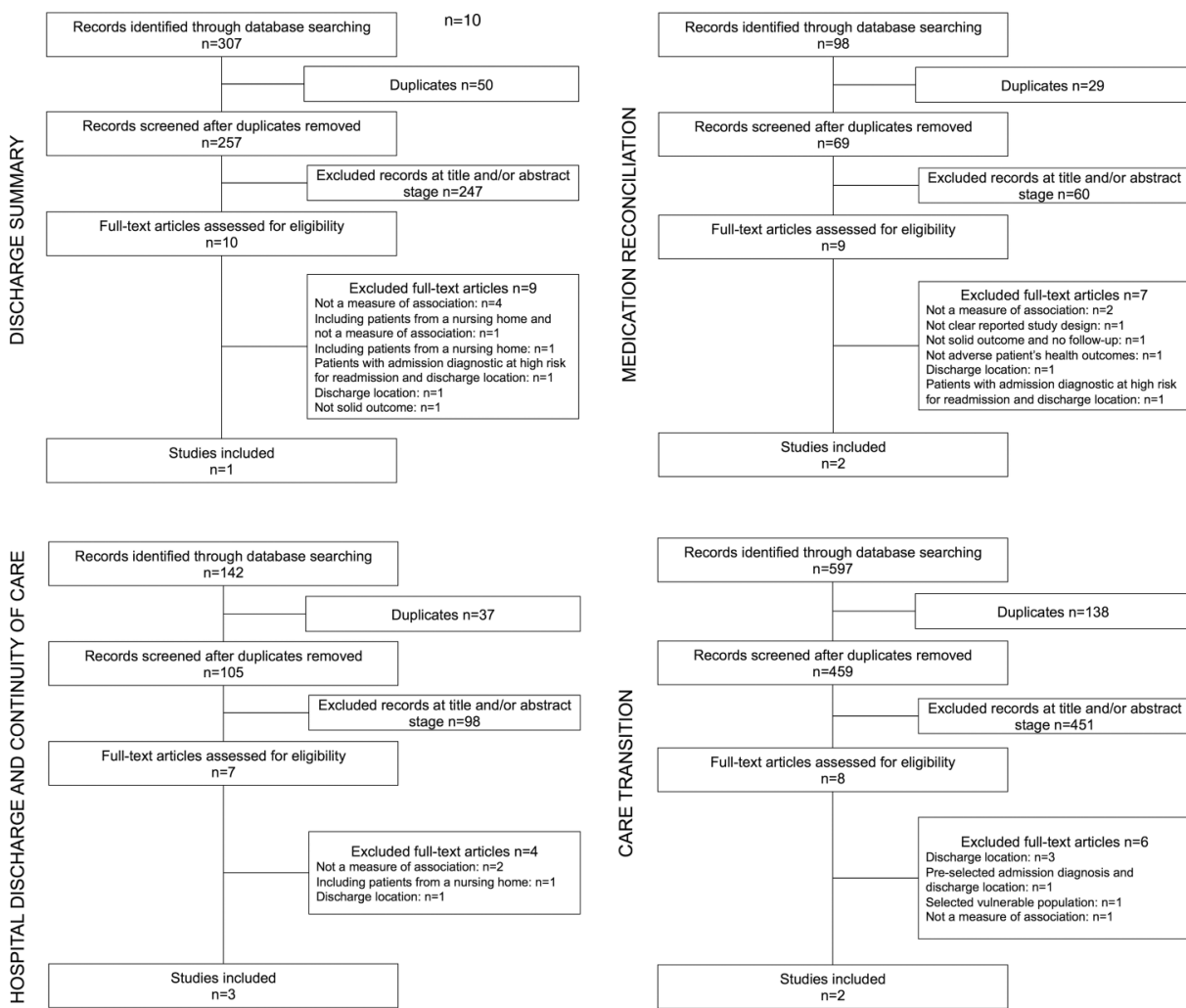

Additional studies identified by updated search made on July 13,2016 : $n=2$
B

Initial included studies through databas searching (four major independent searches): $n=8$

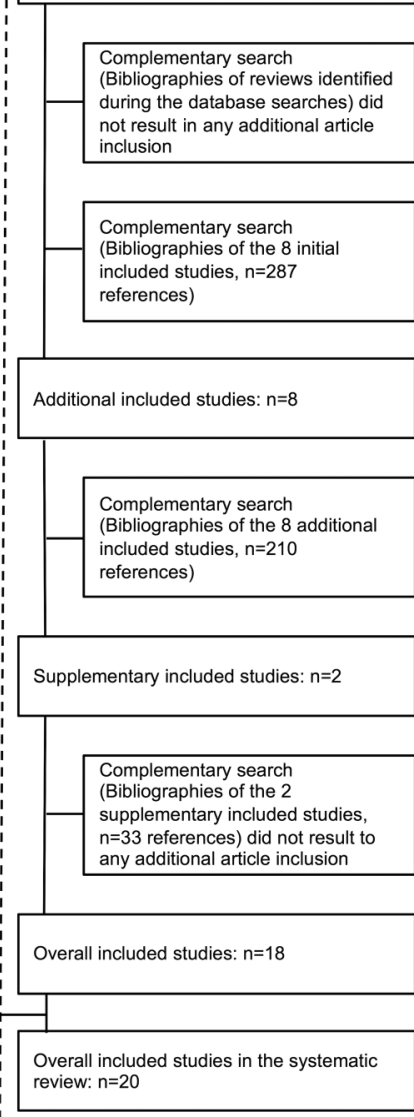

Figure 1 Flow diagram of the systematic review process. (A) Flow diagram of the four independent searches in the Medline and Web of Science databases. (B) Flow diagram of the process for screening the bibliographies of the reviews and initial included studies. 
Figure 2 Methodological quality of the studies included. Dotted determined from the combination of both quality tools (abscissa and ordinate, respectively). lines indicate the quality

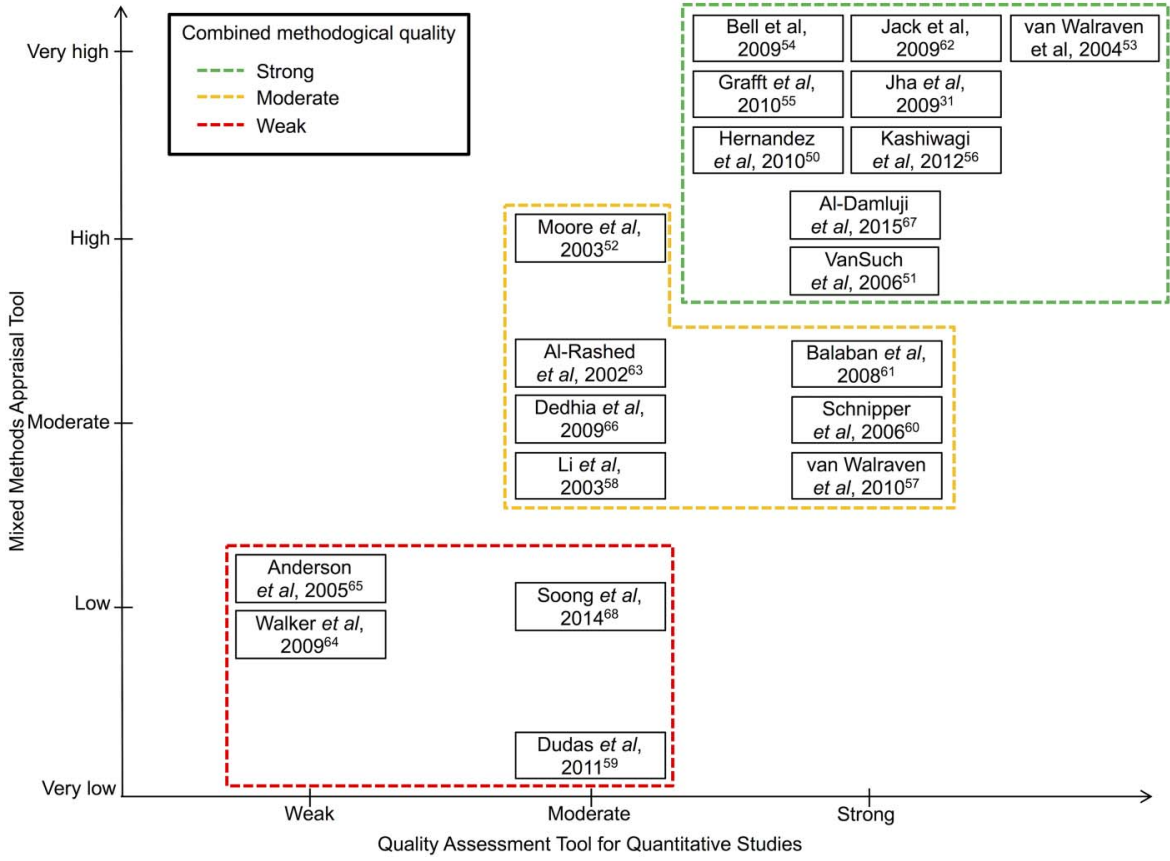

According to the Mixed Methods Appraisal Tool, seven studies were rated as having a very high, ${ }^{31} 50$ 53-56 62 three a high, ${ }^{51} 5267$ six a moderate, ${ }^{57} 5860616366$ three a low $^{646568}$ and one a very low ${ }^{59}$ methodological quality (figure 2).

When the two quality tools were combined, nine studies were rated as having a strong,, ${ }^{31} 505153-566267$ seven a moderate 52575860616366 and four a weak ${ }^{59} 646568$ combined methodological quality (figure 2).

\section{Results of individual studies}

Components of the discharge process investigated

Five discharge process components were explored primarily: discharge summary $(\mathrm{n}=2),{ }^{58} 67$ discharge instructions as mentioned in the medical records $(\mathrm{n}=2), 3151$ drug-related problems at discharge $(\mathrm{n}=4), 59606364$ transition from hospital to home $(\mathrm{n}=5)^{5461626566}$ and continuity of care after hospital discharge $(\mathrm{n}=7)$ (table 1). $.^{50} 525355-5768$

Two observational studies ${ }^{58} 67$ investigated the discharge summary component. One study ${ }^{58}$ examined the timeliness of discharge summary finalisation and the other $^{67}$ investigated the timeliness, documented transmission to the follow-up physician and content of the discharge summary. This component was also explored in two other studies ${ }^{54}$ in combination with other components of the hospital discharge process. In particular, the availability of the discharge summary to the physician during post-discharge visits was investigated.

The component relating to documentation of discharge instructions provided to patients was explored in two observational studies, ${ }^{31}{ }^{51}$ and both concerned patients with congestive heart failure.

Drug-related problems were addressed via the assessment of a pharmacist intervention in four studies. ${ }^{59606364}$ The type and number of intervention elements (eg, pharmaceutical counselling, education, medication review, medication reconciliation, follow-up with a pharmacist after discharge) varied between studies. Similarly, the component 'transition from hospital to home' was explored mainly in four interventional studies, ${ }^{61626566}$ with the number and type of intervention elements (eg, patient therapeutic education, medication reconciliation, post-hospitalisation follow-up) varying between studies. Only one observational study ${ }^{54}$ explored the transition from hospital to home, focusing on different aspects of the communication between hospital staff and primary care physicians (primary care physician's awareness of his or her patient's hospitalisation, receipt of a discharge summary, direct exchanges with the multidisciplinary hospital team).

In contrast, except for a single interventional study that explored the impact of a post-discharge phone call, ${ }^{68}$ the component 'continuity of care after discharge' was investigated exclusively in observational studies. The elements targeted in these studies were documented follow-up appointment arrangements scheduled before discharge ${ }^{55}$ timing of outpatient follow-up after discharge ${ }^{50}{ }^{56}$ post-discharge follow-up by hospital physicians or general practitioners, ${ }^{53}$ a score for continuity of care, ${ }^{57}$ and medical errors related to discontinuity of care from the inpatient to the outpatient setting. ${ }^{52}$

\section{Patient health outcomes after discharge}

The major outcomes measured in the included studies were, in order of frequency, rehospitalisations $(\mathrm{n}=18), 31$ 50-52 54-59 61-68 emergency department visits $(\mathrm{n}=8)^{54} \quad 55 \quad 59 \quad 61 \quad 62 \quad 64 \quad 66 \quad 68$ and mortality $(\mathrm{n}=5)$ (table 1). ${ }^{50} \quad 51 \quad 54 \quad 55 \quad 57$ Two studies investigated only 


\begin{tabular}{|c|c|c|c|c|}
\hline $\begin{array}{l}\text { Discharge } \\
\text { summary }(n=2)\end{array}$ & $\begin{array}{l}\text { Discharge instructions } \\
\text { documented in medical } \\
\text { records }(n=2)\end{array}$ & $\begin{array}{l}\text { Drug-related problems at hospital } \\
\text { discharge }(n=4)\end{array}$ & $\begin{array}{l}\text { Transition from hospital to home } \\
(n=5)\end{array}$ & $\begin{array}{l}\text { Continuity of care after hospital } \\
\text { discharge }(n=7)\end{array}$ \\
\hline \multicolumn{5}{|c|}{ Significant association } \\
\hline $\begin{array}{l}\text { Al-Damluji et } a^{f^{7 \star}} \\
\text { (readmissions at } \\
30 \text { days) }\end{array}$ & $\begin{array}{l}\text { VanSuch et } a^{51 *} \text { (time to } \\
\text { readmission for HF/any } \\
\text { cause at } 12 \text { months) }\end{array}$ & $\begin{array}{l}\text { Al-Rashed et } a^{63} \dagger \text { (readmissions at } \\
15-22 \text { days and } 3 \text { months; unplanned } \\
\text { GP visits at } 15-22 \text { days and } 3 \text { months) }\end{array}$ & $\begin{array}{l}\text { Anderson et } a^{65} \dagger \text { (readmission rate } \\
\text { at } 6 \text { months) }\end{array}$ & $\begin{array}{l}\text { Grafft et } a^{55 \star} \text { (composite end point: ED } \\
\text { visits or readmissions at } 180 \text { days) }\end{array}$ \\
\hline \multirow[t]{3}{*}{$\begin{array}{l}\mathrm{Li} \text { et a }{ }^{88 *} \\
\text { (readmission rate at } \\
7 \text { and } 28 \text { days) }\end{array}$} & & Dudas et $a^{59}+$ (ED visits at 30 days) & $\begin{array}{l}\text { Balaban et } a^{61}+\text { (no follow-up at } \\
21 \text { days) }\end{array}$ & $\begin{array}{l}\text { Hernandez et } a^{50 *} \text { (composite end } \\
\text { point: mortality or readmissions at } \\
30 \text { days; readmissions at } 30 \text { days) }\end{array}$ \\
\hline & & & $\begin{array}{l}\text { Dedhia et } a^{66}+\text { (composite end } \\
\text { point: ED visits or readmissions at } \\
1 \text { week; readmissions at } 30 \text { days) }\end{array}$ & $\begin{array}{l}\text { Moore et } a^{F^{2 *}} \text { (work-up errors and } \\
\text { readmissions at } 3 \text { months) }\end{array}$ \\
\hline & & & $\begin{array}{l}\text { Jack et a }{ }^{62} \dagger \text { (composite end point: } \\
\text { all ED visits and readmissions at } \\
30 \text { days; ED visits at } 30 \text { days; visited } \\
\text { PCP at } 30 \text { days) }\end{array}$ & $\begin{array}{l}\text { van Walraven et } a^{53 *} \text { (composite end } \\
\text { point: death or readmissions at } 30 \text { days) }\end{array}$ \\
\hline \multicolumn{5}{|c|}{ Non-significant association } \\
\hline 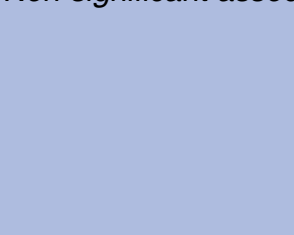 & $\begin{array}{l}\text { Jha et } a^{\beta 1 *} \text { (readmission } \\
\text { rate at } 30 \text { days) }\end{array}$ & $\begin{array}{l}\text { Dudas et } a^{59} \dagger \text { (readmissions at } \\
30 \text { days) }\end{array}$ & $\begin{array}{l}\text { Balaban et } a^{61} \dagger \text { (readmissions at } \\
31 \text { days; ED visits at } 31 \text { days; } \\
\text { incomplete outpatient work-up) }\end{array}$ & $\begin{array}{l}\text { Grafft et } a^{55 *} \text { (composite end point: ED } \\
\text { visits or readmissions at } 30 \text { days; } \\
\text { readmissions at } 30 \text { days; ED visits at } \\
30 \text { days; mortality at } 30 \text { days; } \\
\text { readmissions at } 180 \text { days, mortality at } \\
180 \text { days) }\end{array}$ \\
\hline & $\begin{array}{l}\text { VanSuch et } a^{{ }^{1 *}} \\
\text { (survival time to death } \\
\text { from any cause censored } \\
\text { at } 12 \text { months) }\end{array}$ & $\begin{array}{l}\text { Schnipper et } a^{60} \dagger \text { (composite end } \\
\text { point: ED visits or readmissions at } \\
30 \text { days) }\end{array}$ & $\begin{array}{l}\text { Bell et } a^{5 *} \mp \text { (readmissions at } \\
30 \text { days; } E D \text { visits at } 30 \text { days; death } \\
\text { at } 30 \text { days; composite end point: } \\
\text { readmission or ED visit or death at } \\
30 \text { days) }\end{array}$ & Hernandez et $a^{50 *}$ (mortality at 30 days) \\
\hline & & $\begin{array}{l}\text { Walker et } a^{64} \dagger \text { (readmission rate at } 14 \\
\text { and } 30 \text { days; ED visits at } 72 \text { hours, } \\
14 \text { days, } 30 \text { days; composite end point: } \\
\text { all ED visits and readmissions at } \\
30 \text { days) }\end{array}$ & $\begin{array}{l}\text { Dedhia et } a^{66}+(\text { ED visits at } \\
30 \text { days) }\end{array}$ & $\begin{array}{l}\text { Kashiwagi et } a^{56 *} \text { (readmissions at } \\
30 \text { days) }\end{array}$ \\
\hline & & & $\begin{array}{l}\text { Jack et } a^{{ }^{2}} \dagger \text { (readmissions at } \\
30 \text { days) }\end{array}$ & $\begin{array}{l}\text { Moore et } a^{52 \star} \text { (medication continuity } \\
\text { errors, test follow-up errors and } \\
\text { readmissions at } 3 \text { months) } \\
\text { Soong et } a^{68} \dagger(E D \text { visits at } 30 \text { days; } \\
\text { readmissions at } 30 \text { days) } \\
\text { van Walraven et } a{ }^{57 \star} \ddagger \text { (death at } \\
6 \text { months; readmissions at } 6 \text { months) }\end{array}$ \\
\hline
\end{tabular}


composite outcomes: emergency department visits or rehospitalisations, ${ }^{60}$ and rehospitalisations or mortality. ${ }^{53}$ In addition, six studies investigated outcomes separately and in combination: emergency department visits and/ or rehospitalisations, ${ }^{55626466}$ rehospitalisations or mortality, ${ }^{50}$ and emergency department visits or rehospitalisations or mortality. ${ }^{54}$

The rate of post-discharge visits to a general practitioner was another, less frequently, measured outcome. ${ }^{61-63}$ This outcome was considered from a different perspective in each of three studies: unplanned visits to a general practitioner, ${ }^{63}$ no outpatient follow-up within 21 days $^{61}$ and follow-up visits with the primary care provider. ${ }^{62}$

Follow-up duration after discharge varied from 7 days $^{58}$ to 12 months $^{51}$ for rehospitalisations, from 72 hours ${ }^{64}$ to 31 days $^{61}$ for emergency department visits, from 30 days $^{50} 5455$ to 12 months $^{51}$ for death, and from 15 days $^{63}$ to 3 months $^{63}$ for visits to the general practitioner.

\section{Synthesis of results}

The included studies were published within the past 15 years, suggesting a relatively recent area of investigation. Whereas the studies' underlying healthcare organisations were relatively homogeneous (with most studies originating from the USA), the components of the discharge process investigated were not (see online supplementary file 5). Even when considering a given component category, the variable of interest and the associated investigation method varied widely across studies, including follow-up duration for assessing patient outcome (see table 1), which precluded us from performing a meta-analysis that would generate meaningful results. Nevertheless, the effect of components of the discharge process on the main patient health outcomes is described in figure 3.

In 13 studies, ${ }^{50-53} 55585961-6365-67$ at least one significant association was reported between component(s) of the hospital discharge process and any patient health outcome explored, irrespective of the type of outcomes and the follow-up duration.

Of the 18 studies $^{31}$ 50-52 54-59 61-68 that explored the potential association between hospital discharge process and rehospitalisations, 7 reported a significant association, ${ }^{50} 51586365-67$ while 10 reported a non-significant association. $^{31} \quad 54-575961626468$ The remaining study ${ }^{52}$ evaluated three types of medical errors (work-up errors, medication continuity errors and test follow-up errors) related to the discontinuity of care from the inpatient to the outpatient setting and found a significant association only between work-up errors and rehospitalisations. When the analysis was restricted to the 14 studies $^{31} 50$ 54-56 $58 \quad 59 \quad 61-64 \quad 66-68$ that investigated rehospitalisations within approximately 30 days of discharge (including 15-22 days, ${ }^{63} 28$ days $^{58}$ and 31 days $^{61}$ ), five studies $^{50} 58$ 636667 reported a significant association between this outcome and the hospital discharge process, while nine $^{31} \quad 54-56 \quad 5961 \quad 62 \quad 64 \quad 68$ reported a non-significant association.

Of the eight studies ${ }^{54} 55596162646668$ (six of which were interventional studies) ${ }^{59} 6162646668$ that investigated post-discharge visits to the emergency department as an outcome, two interventional studies ${ }^{59} 62$ reported a

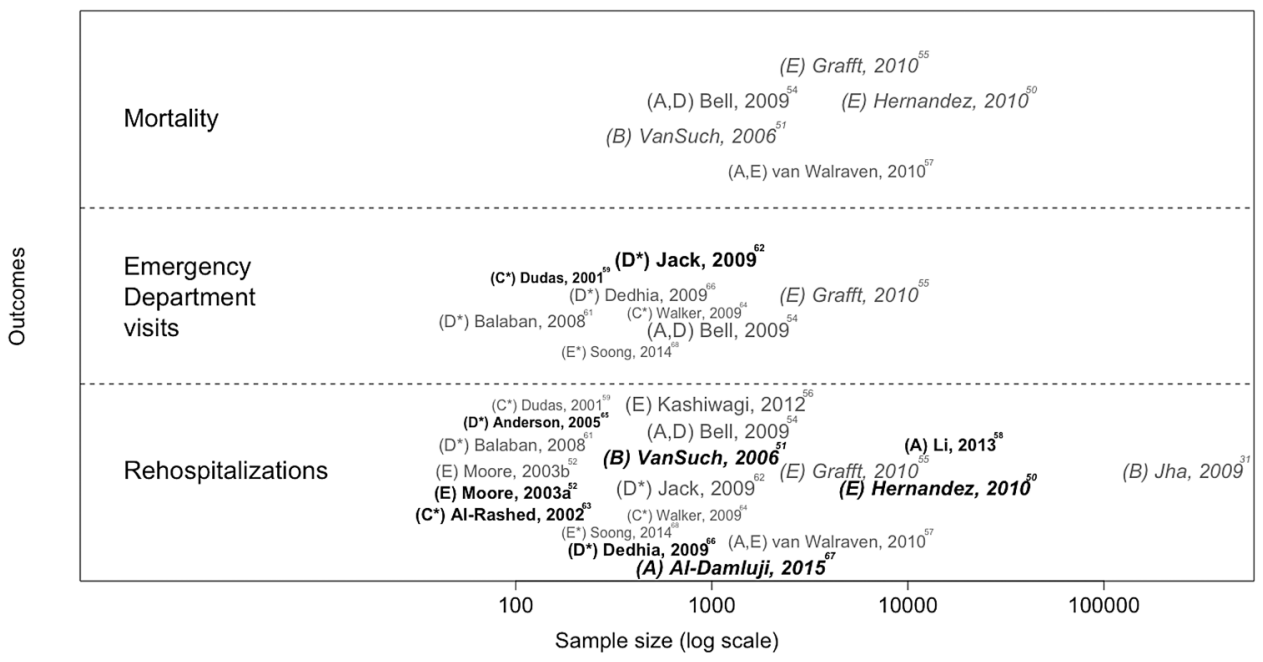

Figure 3 Effect of hospital discharge process and subsequent continuity of care components on patients' health outcomes. The letters in parenthesis correspond to the type of component investigated: A, discharge summary; B, discharge instructions; C, drug-related problems; $D$, transition from hospital to home; and $E$, continuity of care. In addition, interventional studies are identified by an asterisk. Studies in bold and normal characters indicate significant and non-significant associations reported, respectively. Studies in italic characters indicate studies involving patients with heart failure. Small, medium and large sized characters indicate a weak, moderate and strong methodological quality. Moore, 2003a refers to the measured outcome of rehospitalizations related to work-up errors. Moore, $2003 \mathrm{~b}$ refers to the measured outcomes of rehospitalisations related to medication continuity errors and to test follow-up errors. 
significant association between this outcome and the investigated intervention.

The five studies that investigated patient mortality $^{50} 51545557$ were all observational, and all reported no significant association between discharge process and death.

Eight studies ${ }^{50} \quad 53-5560626466$ explored a composite outcome (mostly based on 30-day follow-up duration, $\mathrm{n}=7$ ), the nature of the combination varying from one study to another (table 1 and figure 4). The association between component(s) of the discharge process and subsequent continuity of care and the composite outcome was reported as significant in four studies $^{50} 53 \quad 62 \quad 66$ and as non-significant in three studies. ${ }^{54} 6064$ In the remaining study, ${ }^{55}$ there was no significant association between documented follow-up appointment arrangements and rehospitalisations or emergency department visits within 30 days. However, documented follow-up appointment arrangements were significantly associated with a higher likelihood of having either an emergency department visit or a hospital readmission within 180 days of the initial hospital discharge.

Finally, figures 3 and 4 indicate that irrespective of the component explored, one cannot identify any consistent statistical association between any hospital discharge component and any patient health outcome.

\section{Risk of bias across studies}

Risk of bias across studies was especially difficult to evaluate because of the wide heterogeneity between studies (eg, design, sample size, hospital discharge components, outcomes, follow-up duration). Any correction of a potential publication bias against studies with negative or non-significant associations would have reduced the variability found in this review, with a corresponding mechanic effect favouring consistent absence of an association between discharge organisation and subsequent patient health.

\section{Additional analyses}

No additional analysis was performed.

\section{DISCUSSION}

\section{Summary of evidence}

The major outcomes used to estimate the effect of the discharge process and subsequent continuity of care on patient health after discharge were rehospitalisations and emergency department visits, most commonly measured at approximately 30 days after discharge. Eight of the 18 studies that explored rehospitalisations reported at least one significant association between discharge process and this outcome, while two of the eight studies that investigated emergency department visits reported a significant association. No study reported a significant association between a discharge component and mortality. This systematic review highlights a wide heterogeneity across the studies, especially in terms of the component (s) of the hospital discharge process investigated, study designs and outcomes measured (including follow-up durations). Such a heterogeneity in critical elements prevents a meaningful meta-analysis from being performed. Nevertheless, figures 3 and 4 indicate globally that irrespective of the component of the discharge process explored, outcome considered, sample size or study design, one cannot identify any consistent

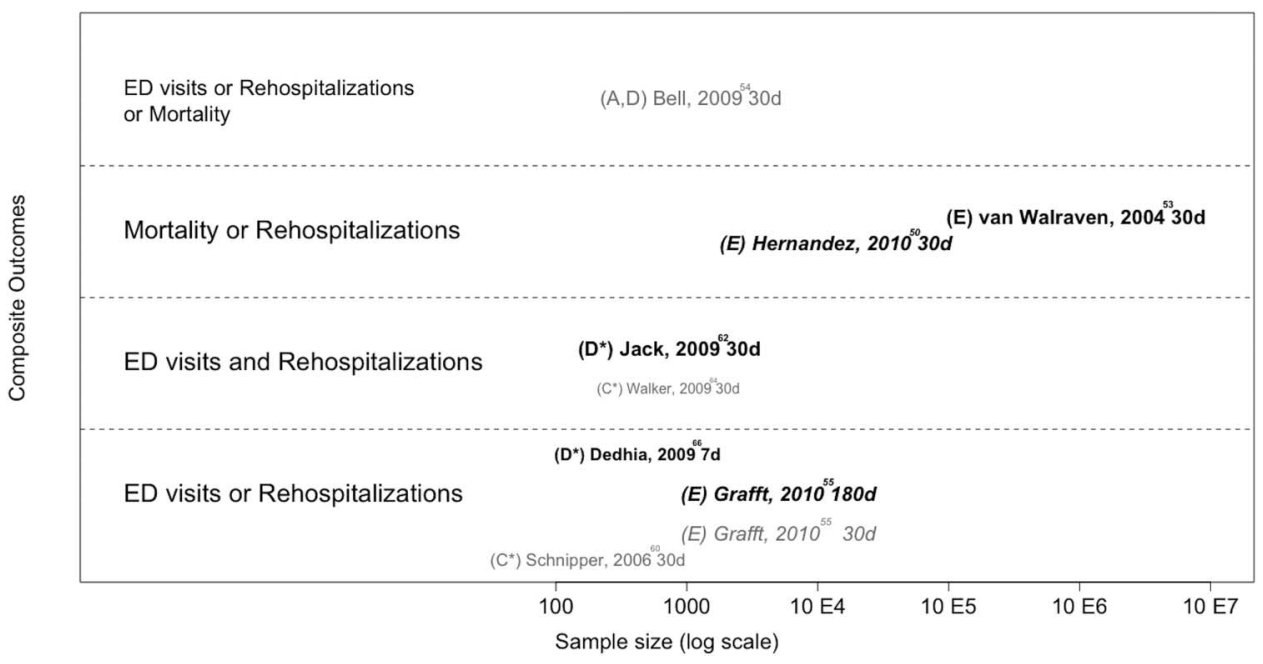

Figure 4 Effect of hospital discharge process and subsequent continuity of care components on patients' composite health outcomes. The letters in parenthesis correspond to the type of component investigated: A, discharge summary; $B$, discharge instructions; C, drug-related problems; D, transition from hospital to home; and E, continuity of care. In addition, interventional studies are identified by an asterisk. Studies in bold and normal characters indicate significant and non-significant associations reported, respectively. Studies in italic characters indicate studies involving patients with heart failure. Small, medium and large sized characters indicate a weak, moderate and strong methodological quality. The follow-up duration in each study is indicated, for example ' $30 \mathrm{~d}$ ' indicates that the follow-up reported is the post-discharge period of 30 days. ED, emergency department. 
statistical association between the presence of a component or an intervention likely improving the quality of the hospital discharge process and an improvement in a patient health outcome. The global picture from our review indicates that the effect of discharge process and subsequent continuity of care components on patient health after discharge remains unclear. Therefore, it is not possible to draw any conclusions about the most critical organisational discharge process components on which to base potential recommendations. This contrasts with the review of Leppin $e t a \vec{l}^{9}$ which indicates that peri-discharge interventions targeting specific populations were effective at reducing hospital readmissions. At least three factors may be contributing to this difference: the heterogeneous general population that was targeted in our review might require very large sample sizes to produce evidence of a comparable impact, personalised interventions in specific populations might be more efficient, and finally study designs involved in our review include observational studies whereas Leppin $e t a l^{39}$ only considered randomised trials. In any case, a major implication of our findings is that better standardisation should be used in future studies in order to get a clearer picture of the impact of discharge elements on the general population of patients. For example, a 30-day readmission delay could be considered as a reasonable standardised outcome (long-term outcomes are probably more liable to be biased by confounding factors).

Among the 20 studies included in this review, nine described interventions, only five of which were randomised trials; this finding raises concerns about the potential effect of confounding factors that might have influenced patient outcomes after discharge. Indeed, in many of the studies, features related to elements of the patients' hospital stay (such as disease progression, severity of illness and comorbidities), which were unrelated to discharge components, may have contributed to patients' health outcomes after discharge.

Another concern is the variability of discharge protocols from one hospital department to another. Such protocols are poorly reported in the studies. ${ }^{50}$ Although 18 of the 20 studies were conducted in the USA $(n=14)$ or Canada $(n=4)$, between-protocol variability might result in variability in the effect of the hospital discharge process on a patient's subsequent health. General recommendations for managing the hospital-primary care interface have been proposed by several societies, ${ }^{69}$ as well as discharge checklists. ${ }^{70}{ }^{71}$ Similarly, Kripalani et $a l^{33}$ attempted to identify challenges and to propose recommendations, given the lack of evidence-based recommendations for hospital discharge applicable to a broad range of patients. However, the rate of adoption of standardised evidence-based recommendations in health organisations remains unknown.

\section{Limitations}

This review is subject to several limitations. First, a single author was involved in critical steps of the review (initial phases leading to article selection, data abstraction and risk assessment of the included studies). This constitutes a significant risk for individual and systematic bias, and thus is a major limitation of this systematic review.

The second limitation concerns the potential omission of relevant studies. However, our iterative process of screening the bibliographies of included studies is likely to have minimised this limitation. Of note, we did not identify any new studies when we searched the bibliographies of reviews identified during the database searches.

The third limitation concerns the populations studied. The inclusion criteria restricted the analysis to studies on general medical or surgical patients originating from home and discharged to home. Studies on specific populations were excluded, but we decided to keep studies involving patients with heart failure given the prevalence of such patients and the substantial volume of literature available on hospital discharge and continuity of care. However, removing the five studies ${ }^{31} 50516567$ involving these patients, shown in italic in figures 3 and 4, would not resolve the above-mentioned absence of identification of any consistent pattern. Moreover, despite the exclusion of studies that were focused on specific populations (see exclusion criterion no. 7 in online supplementary file 2), some of the studies included in the review may not have excluded or measured as a covariate any factor related to frailty or socio-economic status and this may have contributed to the heterogeneity of the results.

The fourth limitation was the heterogeneity revealed by our synthesis of the results. This heterogeneity may be linked to the fact that the processes investigated were complex, multifaceted and interconnected. Previous reviews in the domain of hospital discharge process and continuity of care also report such heterogeneity, ${ }^{35} 363840-45$ likewise attested by the fact that only three reviews performed meta-analyses. ${ }^{37} 3942$

The fifth limitation was the limited scientific evidence of the included studies, given the various designs. Unsurprisingly, studies with a high sample size were observational. Assessment of the methodological quality of the studies indicated that only 9 of the 20 studies were categorised as having a strong score in terms of methodological quality (see figure 2). Finally, one cannot exclude a risk of publication bias against studies that did not find an association between hospital discharge component(s) and patient health outcome(s).

\section{CONCLUSIONS AND PERSPECTIVES}

This systematic review highlights the wide heterogeneity between studies evaluating the effect of the hospital discharge organisation process on patients' outcomes after discharge in a standard population of patients returning home. The role of this heterogeneity in the variance observed in the study results (ie, either a positive effect or absence of effect) is unknown. Globally, the effect of 
the complex interrelated hospital discharge and continuity of care processes on patient health outcomes requires further investigations, but because of the inherent multicomponent nature of these processes and the interweaving of these processes in the entire hospital stay, estimating such an effect is difficult. To obtain a clearer global picture, future studies would benefit from better standardisation of the adverse outcomes explored, including follow-up duration. In addition, technological developments may enhance overall management of patients at the hospital-primary care interface. A major challenge concerns the interoperability between hospital and primary care electronic health information systems, for facilitating exchanges of hospital-primary care information. Moreover, implementation of information systems collecting patient opinions after hospital discharge may document important information on current organisation, and constitute the basis of systems devoted to improving management.

Acknowledgements Sophie Rushton-Smith, PhD (Medlink Healthcare Communications Limited) provided editorial support on the final version of the article and was funded by the authors.

Contributors Study conception and design: BC, FC and GH; data acquisition: $\mathrm{BC}$; analysis and interpretation of data: $\mathrm{BC}$ and $\mathrm{GH}$; writing of the first draft of the paper: $\mathrm{BC}$ and $\mathrm{GH}$; all authors read and approved the final version of the paper.

Funding This work was supported by a grant from Assistance Publique-Hôpitaux de Paris, programme 'Recherche Infirmière' (BC).

Competing interests None declared.

Provenance and peer review Not commissioned; externally peer reviewed.

Data sharing statement No additional data are available.

Open Access This is an Open Access article distributed in accordance with the Creative Commons Attribution Non Commercial (CC BY-NC 4.0) license, which permits others to distribute, remix, adapt, build upon this work noncommercially, and license their derivative works on different terms, provided the original work is properly cited and the use is non-commercial. See: http:// creativecommons.org/licenses/by-nc/4.0/

\section{REFERENCES}

1. Forster AJ, Murff HJ, Peterson JF, et al. The incidence and severity of adverse events affecting patients after discharge from the hospital. Ann Intern Med 2003;138:161-7.

2. Forster AJ, Clark HD, Menard A, et al. Adverse events among medical patients after discharge from hospital. CMAJ 2004;170:345-9.

3. Jencks SF, Williams MV, Coleman EA. Rehospitalizations among patients in the Medicare fee-for-service program. $N$ Engl J Med 2009;360:1418-28.

4. Rising KL, White LF, Fernandez WG, et al. Emergency department visits after hospital discharge: a missing part of the equation. Ann Emerg Med 2013;62:145-50.

5. Vashi AA, Fox JP, Carr BG, et al. Use of hospital-based acute care among patients recently discharged from the hospital. JAMA 2013;309:364-71.

6. Arora VM, Prochaska ML, Farnan JM, et al. Problems after discharge and understanding of communication with their primary care physicians among hospitalized seniors: a mixed methods study. J Hosp Med 2010;5:385-91.

7. Pantilat SZ, Lindenauer PK, Katz PP, et al. Primary care physician attitudes regarding communication with hospitalists. Am J Med 2001;111:15S-20S

8. Horwitz LI, Jenq GY, Brewster UC, et al. Comprehensive quality of discharge summaries at an academic medical center. J Hosp Med 2013;8:436-43.
9. van Walraven $C$, Seth $R$, Laupacis A. Dissemination of discharge summaries-not reaching follow-up physicians. Can Fam Phys 2002;48:737-42.

10. Roy CL, Poon EG, Karson AS, et al. Patient safety concerns arising from test results that return after hospital discharge. Ann Intern Med 2005;143:121-8.

11. Were MC, Li XC, Kesterson J, et al. Adequacy of hospital discharge summaries in documenting tests with pending results and outpatient follow-up providers. J Gen Intern Med 2009;24:1002-6.

12. Moore C, McGinn T, Halm E. Tying up loose ends: discharging patients with unresolved medical issues. Arch Intern Med 2007;167:1305-11.

13. McMillan TE, Allan W, Black PN. Accuracy of information on medicines in hospital discharge summaries. Intern Med $J$ 2006;36:221-5

14. Perren A, Previsdomini M, Cerutti B, et al. Omitted and unjustified medications in the discharge summary. Qual Saf Health Care 2009;18:205-8.

15. Ellitt GR, Engblom E, Aslani P, et al. Drug related problems after discharge from an Australian teaching hospital. Pharm World Sci 2010;32:622-30.

16. Paulino El, Bouvy ML, Gastelurrutia MA, et al. Drug related problems identified by European community pharmacists in patients discharged from hospital. Pharm World Sci 2004;26:353-60.

17. Roughead EE, Kalisch LM, Ramsay EN, et al. Continuity of care: when do patients visit community healthcare providers after leaving hospital? Intern Med J 2011;41:662-7.

18. van Walraven $\mathrm{C}$, Taljaard $\mathrm{M}$, Bell $\mathrm{CM}$, et al. A prospective cohort study found that provider and information continuity was low after patient discharge from hospital. J Clin Epidemiol 2010;63: 1000-10.

19. Coleman EA, Smith JD, Raha D, et al. Posthospital medication discrepancies: prevalence and contributing factors. Arch Intern Med 2005;165:1842-7.

20. Hansen LO, Strater A, Smith L, et al. Hospital discharge documentation and risk of rehospitalisation. BMJ Qual Saf 2011;20:773-8.

21. van Walraven C, Seth R, Austin PC, et al. Effect of discharge summary availability during post-discharge visits on hospital readmission. J Gen Intern Med 2002;17:186-92.

22. Davis MM, Devoe M, Kansagara D, et al. "Did I do as best as the system would let me?" Healthcare professional views on hospital to home care transitions. J Gen Intern Med 2012;27:1649-56.

23. Greysen SR, Schiliro D, Horwitz LI, et al. "Out of sight, out of mind": housestaff perceptions of quality-limiting factors in discharge care at teaching hospitals. J Hosp Med 2012;7:376-81.

24. Harding J. Study of discharge communications from hospital doctors to an inner London general practice. J $R$ Coll Gen Pract 1987;37:494-5.

25. Flacker J, Park W, Sims A. Hospital discharge information and older patients: do they get what they need? J Hosp Med 2007;2:291-6.

26. Hadjistavropoulos $\mathrm{H}$, Biem $\mathrm{H}$, Sharpe $\mathrm{D}$, et al. Patient perceptions of hospital discharge: reliability and validity of a Patient Continuity of Care Questionnaire. Int J Qual Health Care 2008;20:314-23.

27. Horwitz LI, Moriarty JP, Chen C, et al. Quality of discharge practices and patient understanding at an academic medical center. JAMA Intern Med 2013;173:1715-22.

28. Hesselink G, Schoonhoven L, Plas M, et al. Quality and safety of hospital discharge: a study on experiences and perceptions of patients, relatives and care providers. Int J Qual Health Care 2013;25:66-74.

29. Hesselink G, Vernooij-Dassen M, Pijnenborg L, et al. Organizational culture: an important context for addressing and improving hospital to community patient discharge. Med Care 2013;51:90-8.

30. Boulding W, Glickman SW, Manary MP, et al. Relationship between patient satisfaction with inpatient care and hospital readmission within 30 days. Am J Manag Care 2011;17:41-8.

31. Jha AK, Orav EJ, Epstein AM. Public reporting of discharge planning and rates of readmissions. $N$ Engl $J$ Med 2009;361:2637-45.

32. Weiss M, Yakusheva O, Bobay K. Nurse and patient perceptions of discharge readiness in relation to postdischarge utilization. Med Care 2010;48:482-6.

33. Kripalani S, Jackson AT, Schnipper JL, et al. Promoting effective transitions of care at hospital discharge: a review of key issues for hospitalists. J Hosp Med 2007;2:314-23.

34. Kwan JL, Lo L, Sampson M, et al. Medication reconciliation during transitions of care as a patient safety strategy: a systematic review. Ann Intern Med 2013;158:397-403. 
35. Mueller SK, Sponsler KC, Kripalani S, et al. Hospital-based medication reconciliation practices: a systematic review. Arch Intern Med 2012;172:1057-69.

36. Garcia-Caballos M, Ramos-Diaz F, Jimenez-Moleon JJ, et al. Drug-related problems in older people after hospital discharge and interventions to reduce them. Age Ageing 2010;39:430-8.

37. Phillips CO, Wright SM, Kern DE, et al. Comprehensive discharge planning with postdischarge support for older patients with congestive heart failure: a meta-analysis. JAMA 2004;291:1358-67.

38. Hansen LO, Young RS, Hinami K, et al. Interventions to reduce 30-day rehospitalization: a systematic review. Ann Intern Med 2011;155:520-8.

39. Leppin AL, Gionfriddo MR, Kessler M, et al. Preventing 30-day hospital readmissions: a systematic review and meta-analysis of randomized trials. JAMA Intern Med 2014;174:1095-107.

40. Mistiaen P, Poot E. Telephone follow-up, initiated by a hospital-based health professional, for postdischarge problems in patients discharged from hospital to home. Cochrane Database Syst Rev 2006;(4):CD004510.

41. Mistiaen P, Francke AL, Poot E. Interventions aimed at reducing problems in adult patients discharged from hospital to home: a systematic meta-review. BMC Health Serv Res 2007;7:47.

42. Shepperd S, Lannin NA, Clemson LM, et al. Discharge planning from hospital to home. Cochrane Database Syst Rev 2013;(1): CD000313.

43. Hesselink G, Schoonhoven L, Barach $\mathrm{P}$, et al. Improving patient handovers from hospital to primary care: a systematic review. Ann Intern Med 2012;157:417-28.

44. Kripalani S, LeFevre F, Phillips CO, et al. Deficits in communication and information transfer between hospital-based and primary care physicians: implications for patient safety and continuity of care. JAMA 2007;297:831-41.

45. Rennke S, Nguyen OK, Shoeb MH, et al. Hospital-initiated transitional care interventions as a patient safety strategy: a systematic review. Ann Intern Med 2013;158:433-40.

46. Liberati A, Altman DG, Tetzlaff J, et al. The PRISMA statement for reporting systematic reviews and meta-analyses of studies that evaluate health care interventions: explanation and elaboration. PLoS Med 2009;6:e1000100.

47. Jackson N, Waters E, Guidelines for Systematic Reviews in Health Promotion and Public Health Taskforce. Criteria for the systematic review of health promotion and public health interventions. Health Promot Int 2005;20:367-74.

48. Thomas BH, Ciliska D, Dobbins $M$, et al. A process for systematically reviewing the literature: providing the research evidence for public health nursing interventions. Worldviews Evid Based Nurs 2004;1:176-84.

49. Pace $R$, Pluye $P$, Bartlett $G$, et al. Testing the reliability and efficiency of the pilot Mixed Methods Appraisal Tool (MMAT) for systematic mixed studies review. Int J Nurs Stud 2012;49:47-53.

50. Hernandez AF, Greiner MA, Fonarow GC, et al. Relationship between early physician follow-up and 30-day readmission among Medicare beneficiaries hospitalized for heart failure. JAMA 2010;303:1716-22.

51. VanSuch M, Naessens JM, Stroebel RJ, et al. Effect of discharge instructions on readmission of hospitalised patients with heart failure: do all of the Joint Commission on Accreditation of Healthcare Organizations heart failure core measures reflect better care? Qual Saf Health Care 2006;15:414-17.

52. Moore C, Wisnivesky J, Williams S, et al. Medical errors related to discontinuity of care from an inpatient to an outpatient setting. J Gen Intern Med 2003;18:646-51.
53. van Walraven $\mathrm{C}$, Mamdani M, Fang JM, et al. Continuity of care and patient outcomes after hospital discharge. J Gen Intern Med 2004; 19:624-45.

54. Bell CM, Schnipper JL, Auerbach AD, et al. Association of communication between hospital-based physicians and primary care providers with patient outcomes. J Gen Intern Med 2009;24:381-6.

55. Grafft CA, McDonald FS, Ruud KL, et al. Effect of hospital follow-up appointment on clinical event outcomes and mortality. Arch Intern Med 2010;170:955-60.

56. Kashiwagi DT, Burton MC, Kirkland LL, et al. Do timely outpatient follow-up visits decrease hospital readmission rates? Am J Med Qual 2012;27:11-15.

57. van Walraven C, Taljaard M, Etchells E, et al. The independent association of provider and information continuity on outcomes after hospital discharge: implications for hospitalists. J Hosp Med 2010;5:398-405.

58. Li JYZ, Yong TY, Hakendorf $P$, et al. Timeliness in discharge summary dissemination is associated with patients' clinical outcomes. J Eval Clin Pract 2013;19:76-9.

59. Dudas V, Bookwalter T, Kerr KM, et al. The impact of follow-up telephone calls to patients after hospitalization. Am J Med Qual 2001;111:26S-30S

60. Schnipper JL, Kirwin JL, Cotugno MC, et al. Role of pharmacis counseling in preventing adverse drug events after hospitalization. Arch Intern Med 2006;166:565-71.

61. Balaban RB, Weissman JS, Samuel PA, et al. Redefining and redesigning hospital discharge to enhance patient care: a randomized controlled study. J Gen Intern Med 2008;23:1228-33.

62. Jack BW, Chetty VK, Anthony D, et al. A reengineered hospital discharge program to decrease rehospitalization: a randomized trial. Ann Intern Med 2009;150:178-87.

63. Al-Rashed SA, Wright DJ, Roebuck N, et al. The value of inpatient pharmaceutical counselling to elderly patients prior to discharge. $\mathrm{Br}$ $J$ Clin Pharmacol 2002:54:657-64.

64. Walker PC, Bernstein SJ, Jones JN, et al. Impact of a pharmacist-facilitated hospital discharge program: a quasi-experimental study. Arch Intern Med 2009;169:2003-10.

65. Anderson C, Deepak BV, Amoateng-Adjepong Y, et al. Benefits of comprehensive inpatient education and discharge planning combined with outpatient support in elderly patients with congestive heart failure. Congest Heart Fail 2005;11:315-21.

66. Dedhia P, Kravet S, Bulger J, et al. A quality improvement intervention to facilitate the transition of older adults from three hospitals back to their homes. J Am Geriatr Soc 2009;57:1540-6.

67. Al-Damluji MS, Dzara K, Hodshon B, et al. Association of discharge summary quality with readmission risk for patients hospitalized with heart failure exacerbation. Circ Cardiovasc Qual Outcomes 2015:8:109-11.

68. Soong C, Kurabi B, Wells D, et al. Do post discharge phone calls improve care transitions? A cluster-randomized trial. PLOS ONE 2014;9:e112230.

69. Snow V, Beck D, Budnitz T, et al. Transitions of Care Consensus policy statement: American College of Physicians, Society of General Internal Medicine, Society of Hospital Medicine, American Geriatrics Society, American College of Emergency Physicians, and Society for Academic Emergency Medicine. J Hosp Med 2009;4:364-70.

70. Halasyamani L, Kripalani S, Coleman E, et al. Transition of care for hospitalized elderly patients-development of a discharge checklist for hospitalists. J Hosp Med 2006;1:354-60.

71. Soong C, Daub S, Lee J, et al. Development of a checklist of safe discharge practices for hospital patients. J Hosp Med 2013;8:444-9. 